See Article page 1839.

\section{Commentary: Minimally invasive direct coronary artery bypass for isolated left anterior descending lesions: A welcomed innovation}

\author{
Rodolfo V. Rocha, MD, ${ }^{\mathrm{a}}$ Derrick Y. Tam, MD, ${ }^{\mathrm{a}, \mathrm{b}}$ and \\ Stephen E. Fremes, MD, MSc ${ }^{\mathrm{a}, \mathrm{b}}$
}

Significant flow-limiting lesions of the left anterior descending (LAD) artery may lead to myocardial infarction and death. ${ }^{1}$ The 2012 American College of Cardiology Foundation/American Heart Association revascularization guidelines provide a greater class of recommendation for coronary artery bypass grafting with the use of the left internal mammary artery (LIMA) (Class IIa) versus percutaneous coronary intervention (PCI) (Class IIb) to treat these isolated lesions. ${ }^{2}$ Despite this, PCI is usually preferred by patients due to its decreased invasiveness and faster recovery. As well, in-stent restenosis has decreased with wide adoption of drug-eluting stent (DES) platforms. ${ }^{3}$ The invasiveness of coronary artery bypass grafting has been addressed through innovations to avoid sternotomy and cardiopulmonary bypass. Minimally invasive direct coronary artery bypass (MIDCAB), as described by the authors in this issue of the Journal, is one such technique. The LIMA is robotically harvested and the LIMA-LAD anastomosis is performed under direct vision via sternal-sparing mini-thoracotomy. ${ }^{4}$

Patel and colleagues ${ }^{4}$ compared the results of PCI with DES with MIDCAB in patients with isolated LAD lesions requiring revascularization. In a propensity-score matched analysis, there was no difference in 9-year survival in 158

\footnotetext{
From the a Division of Cardiac Surgery, Schulich Heart Centre, Department of Surgery, Sunnybrook Health Sciences Centre; and ${ }^{\mathrm{b}}$ Institute of Health Policy, Management and Evaluation, University of Toronto, Toronto, Ontario, Canada.

Disclosures: Dr Tam is supported by a CIHR Fellowship (Canada). Dr Fremes is supported by the Bernard S. Goldman Chair in Cardiovascular Surgery (Toronto, Ontario). Dr Rocha reported no conflicts of interest.

The Journal policy requires editors and reviewers to disclose conflicts of interest and to decline handling or reviewing manuscripts for which they may have a conflict of interest. The editors and reviewers of this article have no conflicts of interest.

Received for publication May 19, 2020; accepted for publication May 20, 2020; available ahead of print June 5, 2020.

Address for reprints: Stephen E. Fremes, MD, MSc, Schulich Heart Centre, Sunnybrook Health Sciences Centre, 2075 Bayview Ave, Room H4 05, Toronto, Ontario, M4N 3M5 Canada (E-mail: stephen.fremes@sunnybrook.ca).

J Thorac Cardiovasc Surg 2022;163:1847-8

$0022-5223 / \$ 36.00$

Copyright (c) 2020 by The American Association for Thoracic Surgery

http://dx.doi.org/10.1016/j.jtcvs.2020.05.075
}

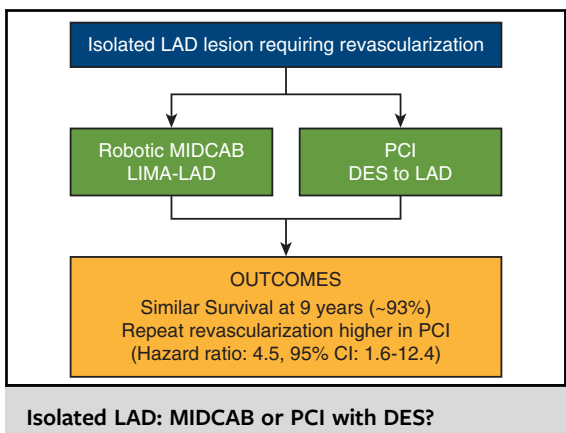

CENTRAL MESSAGE

As surgeons, we must strive to innovate, to provide state-of-theart treatment options for our patients. Patel and colleagues show that MIDCAB for isolated LAD lesions is a welcomed innovation.

well-matched patient-pairs. Nonetheless, the risk of repeat revascularization was greater with DES-PCI, which was strongly associated with smaller stent diameter. Counterintuitively, age was not a risk variable for mortality after MIDCAB but was for DES-PCI. Also, aggregate costs, which included the costs of repeat revascularization, were greater in the PCI arm, using the institution's financial system. Overall, these findings suggest that when performed in experienced hands, MIDCAB is a safe, minimally invasive alternative to revascularize the LAD with excellent longterm results.

However, this study must be interpreted in the context of some important limitations. Their single-center results with MIDCAB are not generalizable, inasmuch as most institutions do not have a robotics program. In addition, there is a learning curve with robotic surgery, leading to long procedural times with greater rates of adverse events in the beginning of the robotic experience. ${ }^{5}$ The surgical group at Lennox Hill is well past their learning curve. Furthermore, the upfront capital costs to set up a robotics practice are substantial. These may be reasons why MIDCAB is not widely adopted in the surgical community. The use of propensity-score matching can only adjust for measured baseline demographics but cannot adjust for unmeasured variables, including the ultimate physician decision of one therapy over another. Also, other important cardiac events were not reported. Finally, the study might be underpowered to show any clinical difference between techniques due to the small sample size. 
Nonetheless, we congratulate the authors on this timely analysis with extensive long-term follow-up. Overall, the outcomes were excellent with both approaches. Although current guidelines have a stronger recommendation for bypass surgery than PCI for isolated LAD disease, the findings of the ISCHEMIA (International Study of Comparative Health Effectiveness with Medical and Invasive Approaches) investigators suggest that an initial noninvasive approach is a reasonable strategy for many patients with stable ischemic heart disease. ${ }^{6}$ The decision to revascularize and the mode of revascularization for any individual patient should ideally be performed in a Heart Team setting, as was done in this study. Patel and colleagues illustrate that MIDCAB can be the procedure of choice, particularly for patients with nonfavorable lesion characteristics for PCI and if a patient has a longanticipated life expectancy. As PCI options continue to evolve and improve, as surgeons, we must also strive to innovate, to provide state-of-the-art treatment options for our patientsthis study by Patel and colleagues shows that MIDCAB for isolated LAD lesions is a welcomed innovation.

\section{References}

1. Doenst T, Haverich A, Serruys P, Bonow RO, Kappetein P, Falk V, et al. PCI and $\mathrm{CABG}$ for treating stable coronary artery disease: JACC review topic of the week. J Am Coll Cardiol. 2019;73:964-76.

2. Fihn SD, Gardin JM, Abrams J, Berra K, Blankenship JC, Dallas AP, et al. 2012 ACCF/AHA/ACP/AATS/PCNA/SCAI/STS guideline for the diagnosis and management of patients with stable ischemic heart disease: a report of the American College of Cardiology Foundation/American Heart Association task force on practice guidelines, and the American College of Physicians, American Association for Thoracic Surgery, Preventive Cardiovascular Nurses Association, Society for Cardiovascular Angiography and Interventions, and Society of Thoracic Surgeons. J Am Coll Cardiol. 2012;60:e44-164.

3. Palmerini T, Benedetto U, Biondi-Zoccai G, Della Riva D, Bacchi-Reggiani L, Smits PC, et al. Long-term safety of drug-eluting and bare-metal stents: evidence from a comprehensive network meta-analysis. J Am Coll Cardiol. 2015;65: 2496-507.

4. Patel NC, Hemli JN, Seetharam K, Singh VP, Scheinerman J, Pirelli L, et al. Minimally-invasive coronary bypass versus percutaneous coronary intervention for isolated complex stenosis of the left anterior descending coronary artery. $J$ Thorac Cardiovasc Surg. 2022;163:1839-46.e1.

5. Oehlinger A, Bonaros N, Schachner T, Ruetzler E, Friedrich G, Laufer G, et al. Robotic endoscopic left internal mammary artery harvesting: what have we learned after 100 cases? Ann Thorac Surg. 2007;83:1030-4.

6. Maron DJ, Hochman JS, Reynolds HR, Bangalore S, O’Brien SM, Boden WE, et al. Initial invasive or conservative strategy for stable coronary disease. $N$ Engl J Med. 2020;382:1395-407.
See Article page 1839.

\section{Commentary: Is robotic-assisted coronary bypass ready for prime time?}

\section{Danny Ramzy, MD, $\mathrm{PhD}$, and Joanna Chikwe, MD, FRCS}

Minimally invasive direct coronary artery bypass (MID$\mathrm{CAB}$ ) has been plagued by challenges since its inception over 25 years ago. These center around its highly technical

From the Department of Cardiac Surgery, Smidt Heart Institute, Cedars-Sinai Medical Center, Los Angeles, Calif.

Disclosures: Dr Chikwe: Cedars-Sinai Medical Center receives honoraria from Edwards-Lifesciences and Medtronic for speaker and consulting activity. Dr Ramzy reported no conflicts of interest.

The Journal policy requires editors and reviewers to disclose conflicts of interest and to decline handling or reviewing manuscripts for which they may have a conflict of interest. The editors and reviewers of this article have no conflicts of interest.

Received for publication May 24, 2020; accepted for publication May 25, 2020; available ahead of print June 16, 2020.

Address for reprints: Joanna Chikwe, MD, FRCS, Department of Cardiac Surgery, Smidt Heart Institute Cedars-Sinai Medical Center, Beverly Hills, Los Angeles, CA 90048 (E-mail: Joanna.chikwe@ cshs.org).

J Thorac Cardiovasc Surg 2022;163:1848-50

0022-5223/\$36.00

Copyright (c) 2020 by The American Association for Thoracic Surgery

http://dx.doi.org/10.1016/j.jtcvs.2020.05.074
Check for updates

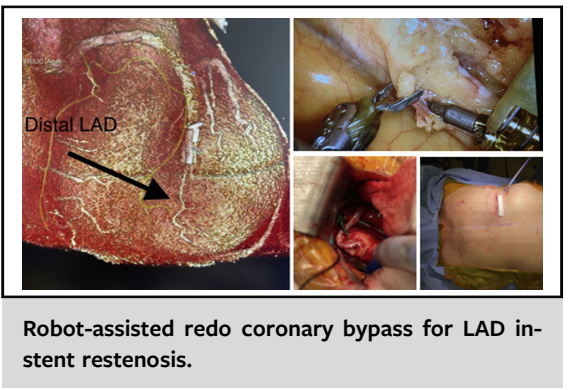

CENTRAL MESSAGE

Robot-assisted coronary bypass

may have survival benefits over

drug-eluting stents in older and

obese patients with isolated,

complex LAD stenosis.

nature: It can be challenging to harvest the entire internal thoracic artery and identify the left anterior descending (LAD) coronary artery via a minithoracotomy, and anatomic factors such as obesity, reoperation, and intramyocardial 